\title{
Ecogenetic monitoring of ionizing radiation for radon-hazardous territories
}

\author{
Zarema Biyasheva, Vyacheslav Dyachkov, Yuliya Zaripova*', Aisha Shaizadinova, Bibizhan \\ Ikhsanova, Aizhan Medeubayeva and Aidana Stvayeva \\ al-Farabi Kazakh National University, 050040 al-Farbi 71, Almaty, Kazakhstan
}

\begin{abstract}
This work is devoted to studying the alpha activity distribution of natural radionuclides in boarding schools located near zones of tectonic faults. There are many tectonic faults in the Almaty and this is the basis for referring the southern capital of Kazakhstan to the radon-hazardous territories. As a result of radiometric measurements a 2D-topology of the alpha-radiation flux density distribution from the distance to the tectonic fault was found. Based on the measurements results the coefficient of radon concentration from the distance to the tectonic rupture was found. Using the obtained pattern, it is possible to plot the dependence of volumetric alpha activity for other schools, if their distances from the tectonic fault are known. In addition, interest in biomedical and ecogenetic effects of radon and its decay products has grown considerably in the last few years. These effects have been investigated in biotests on Drosophila's two systems. It was found that alpha-particles, with the help of which the situation in radon-hazardous territories was simulated, possess mutagenic influence manifested mainly in formation of morphoses or deformities.
\end{abstract}

\section{Introduction}

About $50 \%$ of the Earth's natural radiation is caused by gas of radon and the products of its decay $[1,2]$. Radon is released from the Earth's crust everywhere and its concentration differs significantly for different points of the globe. Almaty region may be referred to radon dangerous territories due to the presence of many tectonic faults that intensify radon emanation. In view of the above, the aim of this work was to calculate the decline coefficient of the barometric formula (radon concentration coefficient) depending on the distance to the tectonic fault and to study the genetic effects of excessive doses of radon exposure on the alpha-radiation model. Using the obtained coefficient it is possible to plot dependence of volumetric alpha-activity for the object, if its distance from the tectonic fault is known.

\footnotetext{
${ }^{*}$ Corresponding author: zjkaznu2016@gmail.com
} 


\section{Radioecological monitoring near tectonic faults}

The world literature data show that elevated levels of radon emanations are associated precisely with existing tectonic faults [3-5]. Therefore, residential and administrative facilities located in the zone of tectonic faults were chosen for the study. This is the "House of Hope" for children temporarily deprived of parental care (\#1). General education boarding school №10 for children from low-income families (\#2). General education boarding school №17 (\#3).

Measurements were taken using modern electronic radiometric instrumentation of the following types: alpha-dosimeter "RKS-01A-SOLO"; beta-dosimeter "RKS-01B-SOLO"; gamma-dosimeter "RKS-01G-SOLO". In order to study vertical distribution of radon isotopes by height, a scheme was developed for each floor of the building, starting from the basement up to the roof. As result of measurement was created a 2D-topology of radon and its DDP alpha-radiation flux density distribution by measurement height (floor) for each boarding school and 2D-topology of radon and its DDP alpha-radiation flux density distribution by distance from the tectonic rupture. The calculation coefficient of radon concentration by distance from the tectonic fault was found: $K_{R n}=0.0002 r+0.046$, where $r-$ is the distance from the tectonic fault.

particle $/\left(\min ^{*} \mathrm{~cm}^{2}\right)$

Using the obtained pattern, we can plot the dependence of volumetric alpha activity for other schools, if their distances from the tectonic fault are known (Fig.2).

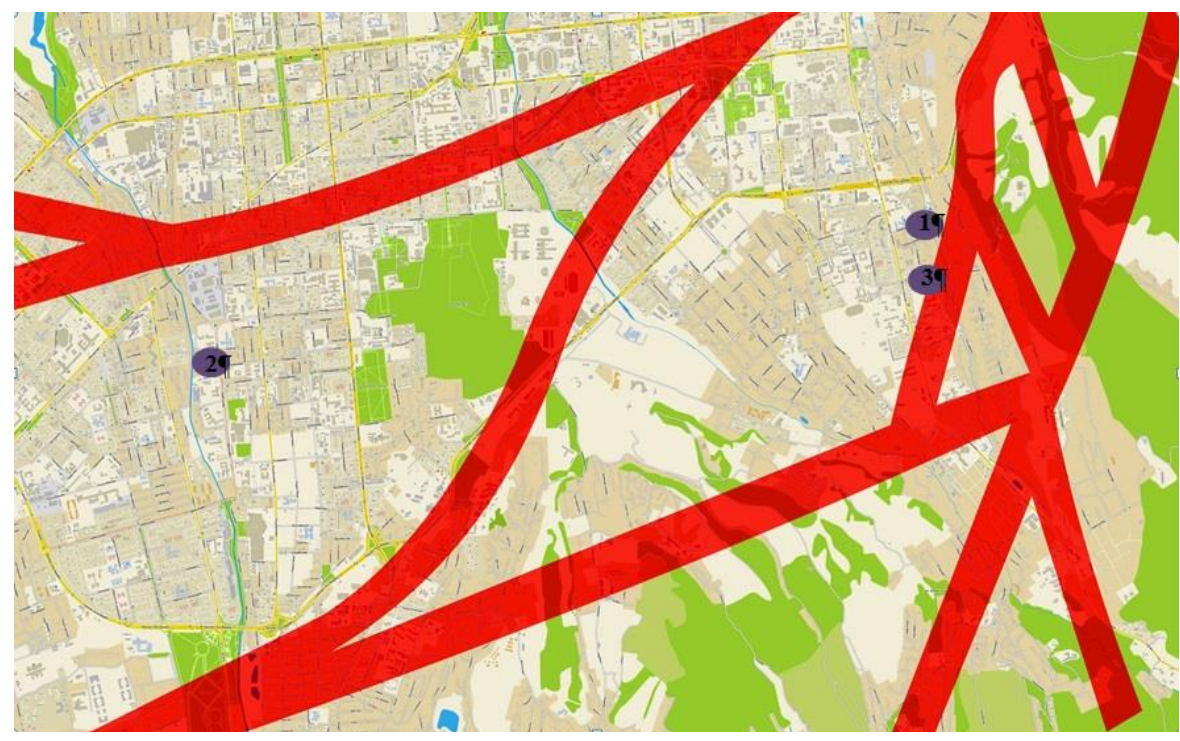

Fig. 1. Location of boarding schools in Almaty city. Influence of the distance from the place of measurement to the tectonic fault (meters) on the radiation level.

The conformity of radon volumetric activity with the barometric formula of exponential decline in activity with increasing altitude was verified. In school \#2 (1060 m from the fault) alpha-activity decreases with increasing number of storeys, which is less pronounced in schools \# 1 (223 m from the fault) and \#3 (190 m from the fault), which is probably due to their proximity to tectonic faults: the decrease coefficient of the barometric formula (radon concentration factor) has a greater value for school \#2 (Fig. 2). Similarly, the level of alpha flux density is higher for schools \#1 and \#3 in comparison with school \#2, which is more distant from the fault (Fig. 3) 


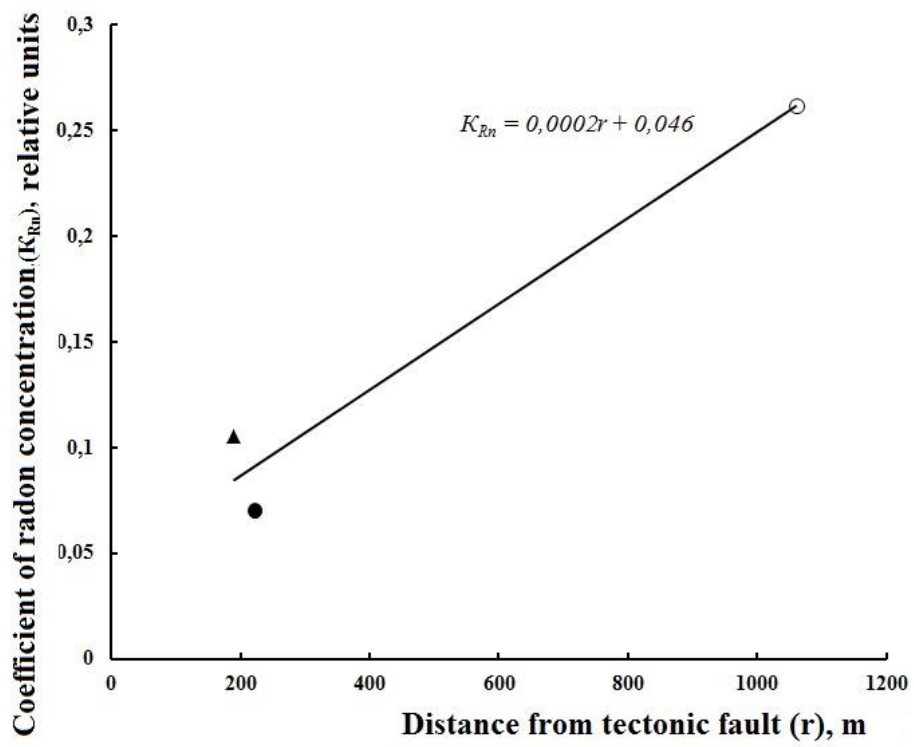

Fig. 2. Dependence of radon concentration coefficients on the distance to the tectonic fault.

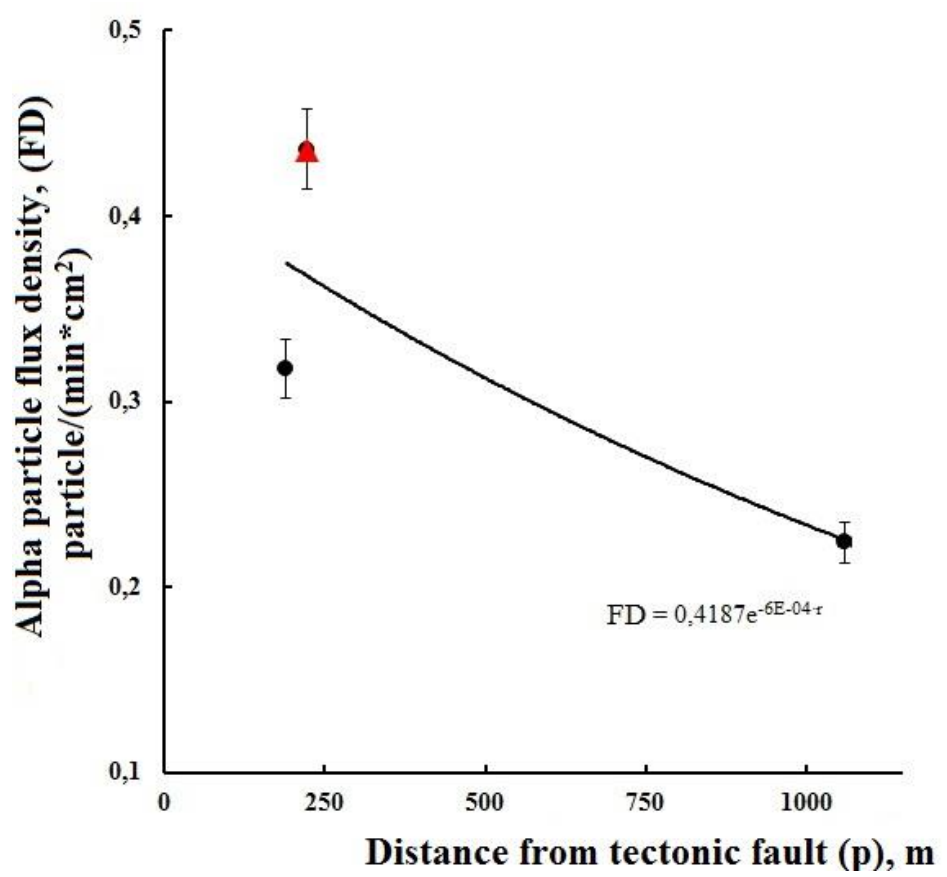

Fig. 3. $\Delta$ - school \#1 (double tectonic fault). Dependence of alpha flux density on the distance to the tectonic fault. 


\section{Radon biotesting in the alpha radiation model}

At the radon and its daughter decay products contamination sites radiation control is carried out and doses of alpha-radiation are measured. The measured level can be used in monitoring as well as simulated in an experiment using biotests [6]. Therefore, to determine the possible genetic effects of physical or chemical agents, including radon and its decay products, special sets of tests that meet sensitivity and specificity requirements are used rather than individual tests.

Two test systems were used: with X-linked chromosome and simultaneously with Xlinked chromosome and X-Y-linked chromosome of Drosophila. We investigated the epigenetic effects of alpha particles, which in the environment are mainly generated by radon and its isotopes. In experiments as a source of alpha-particles we used (Fig. 4) isotope of plutonium-238 $\left(\mathrm{Pu}^{238}\right)$ generating radiation with energy of about $5500 \mathrm{keV}$ as well as radium-226 $\left(\mathrm{Ra}^{226}\right)$ and triplet $\left(\mathrm{Pu}^{238}+\mathrm{Pu}^{239}+\mathrm{U}^{233}\right)$.

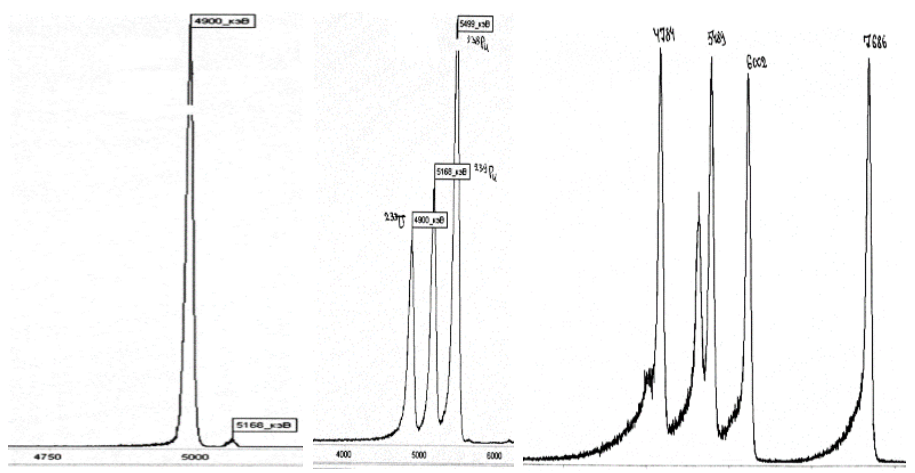

Fig. 4. $\boldsymbol{\Delta}$ - a) $238 \mathrm{Pu}$; b) $233 \mathrm{U}+239 \mathrm{Pu}+238 \mathrm{Pu}$; c) $226 \mathrm{Ra}$ (full analogue of $222 \mathrm{Rn}$ decay chain). Spectra of alpha sources used in cell irradiation experiments.

In experiments with $\mathrm{Pu}^{238}$ in the first generation (F1), deformities, or morphoses, which can be called "radiation syndromes" or mutations, whose manifestation is similar to the pleiotropic effect of genes or disruption in the genetic development program, were detected (Fig. 5-6). The proportion of morphoses in the 1-112 test system was $1.8 \%$ in the experiment and $0.4 \%$ in the control. In the EP-2 test system proportion was $2.02 \%$ in the experiment and $0.39 \%$ in the control. Figures 5 and 6 show the morphoses of the first generation flies (F1). The results of the experiment with $\mathrm{Ra}^{226}$ and triplet showed similar values.
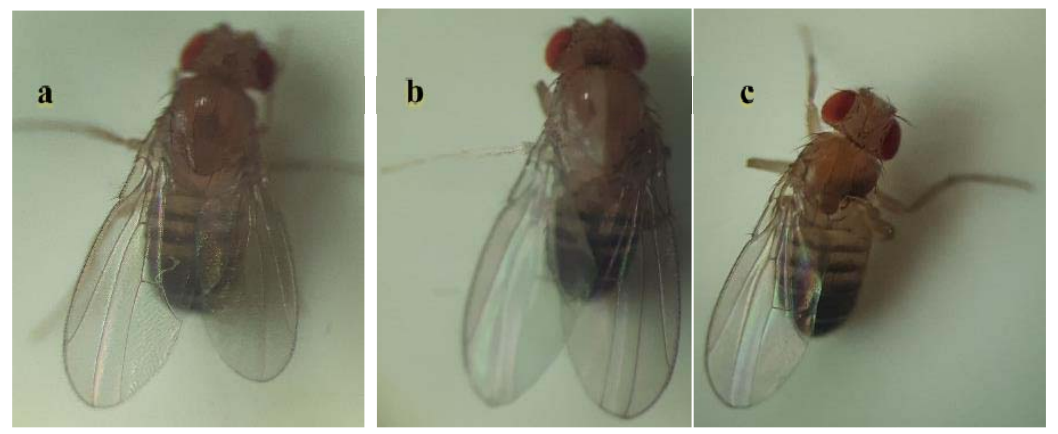

Fig. 5. Detected Pu238-induced morphoses in F1 flies in test system 1-112: (a) shortened right wing; (b) change in thorax coloration or "glazing" (c) absence of one wing with thorax deformation. 


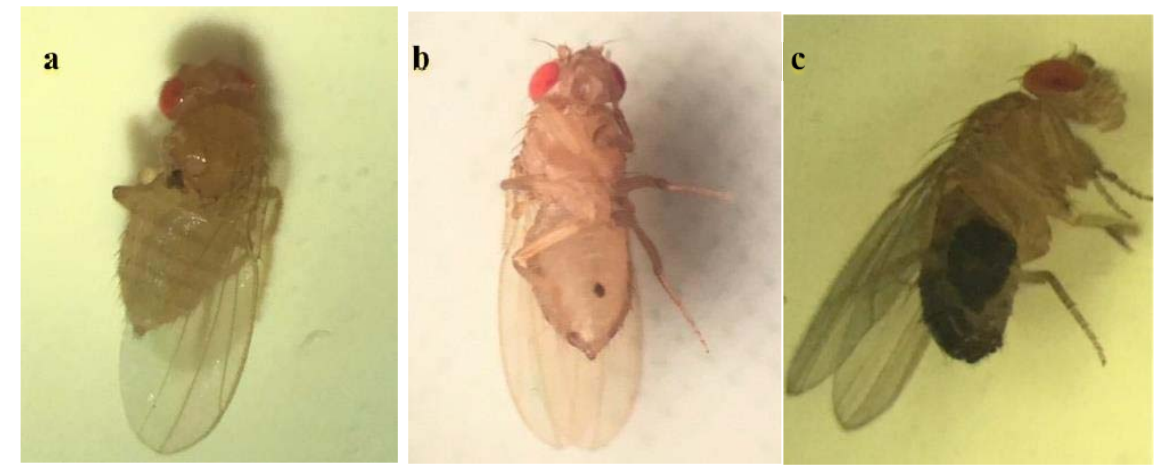

Fig. 6. Detected Pu238-induced morphoses in F1 flies in test system 1-112: (a) shortened right wing; (b) change in thorax coloration or "glazing" (c) absence of one wing with thorax deformation.

Morphoses in Drosophila flies of the first and second generations appeared as black spots or melanomas on various parts of the imago body; "generalized" melanomas; twisted, curved wings; shortened wing; blistering on one wing; absence of one wing, deformation of thorax, interruption and violation of tergite patterns, violation of distribution of eye facets and hairs; pigmentation absence of second and third legs.

\section{Conclusion}

Statistical analysis by Chi-square method showed a significant difference in the mutation level in the experiment with $\mathrm{Pu}^{238}$ and the control at $\mathrm{P} \leq 0.01$. Statistical analysis of data from the experiments with $\mathrm{Ra}^{226}$ and triplet significantly confirmed the mutagenic effect at a probability level of $\mathrm{P} \leq 0.01$. On the basis of this, it can be assumed that alpha-particles which were used to simulate the situation in radon-hazardous areas have a mutagenic effect manifested mainly in the formation of morphosis or deformities.

The work was performed with the support of the state grant funding of basic research of the Republic of Kazakhstan (AP09258978, AP09058404).

\section{References}

1. ICRP Publication 65. Protection Against Radon-222 at Home and at Work, Ann. ICRP 23(2), 1-45 (1993)

2. ICRP Publication 50. Lung Cancer Risk from Exposures to Radon Daughters, Ann. ICRP 17(1), 1-60 (1987)

3. Z. Chen, Y. Li, Z. Liu, J. Wang, X. Zhou, J. Du, Sci Rep 8, 16772 (2018)

4. M. Neri, S. Giammanco, E. Ferrera, G. Patane, V. Zanon, J. of Env. Radioactivity, 102(9), 863-870 (2011).

5. J. Vaupotic, et al, Natural Hazards \& Earth System Sciences, 10(4), 1-6 (2010).

6. A. Lovinskaya, et al., Ecological genetics, 17(2), 69-81 (2019). 